6 - ORIGINAL ARTICLE

WOUND HEALING

\title{
Antibacterial properties and healing effects of Melipona scutellaris honey in MRSA- infected wounds of rats $^{1}$
}

\author{
Vanessa de Fátima Lima Paiva Medeiros ${ }^{\mathrm{I}}$, Ítalo Medeiros Azevedo ${ }^{\mathrm{I}}$, Amália Cínthia Meneses Rêgo ${ }^{\mathrm{II}}$, Eryvaldo Sócrates Tabosa \\ do Egito ${ }^{I I I}$, Irami Araújo-Filho ${ }^{\text {IV }}$, Aldo Cunha Medeiros ${ }^{\mathrm{V}}$ \\ DOI: http://dx.doi.org/10.1590/S0102-865020160050000006 \\ ${ }^{\mathrm{I}}$ Fellow PhD degree, Postgraduate Program in Health Sciences, Universidade Federal do Rio Grande do Norte (UFRN), Natal-RN, Brazil. Acquisition \\ and interpretation of data, manuscript preparation. \\ IIAssociate Professor, Universidade Potiguar, Lauriate International Universities, Natal-RN, Brazil. Technical procedures, acquisition of data. \\ IIIFull Professor, Department of Fharmacy, UFRN, Natal-RN, Brazil. CNPq/PQ.1D fellowship. Analysis and interpretation of data, technical procedures, \\ critical revision. \\ ${ }^{\mathrm{IV}} \mathrm{PhD}$, Associate Professor, Nucleus of Experimental Surgery, Department of Surgery, UFRN, Natal-RN, Brazil. Analysis and interpretation of data, \\ technical procedures, critical revision.

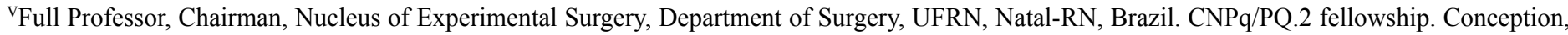 \\ design, intellectual and scientific content of the study; analysis and interpretation of data; technical procedures; critical revision.
}

\section{ABSTRACT}

PURPOSE: To investigate the antimicrobial, immunological and healing effects of Melipona scutellaris honey on infected wounds of rat skin.

METHODS: Twenty four Wistar rats were distributed in four groups (6-each). The uninfected skin wounds of group I rats were treated daily with saline for 7 days. Uninfected wounds (group II) rats were treated with honey. In group III (treated with saline) and group IV (treated with honey) wounds were inoculated with MRSA ATTC43300. The first bacterial culture was performed 24 hours later. In the $7^{\text {th }}$ day new culture was done, and wound biopsies were used for cytokines dosage and histopathology.

RESULTS: In group I and III rats the CFU/g count of $S$. aureus in wounds was zero. In group II rats the CFU/g counts in the wound tissue were significantly higher than in wounds of group IV rats. The density histopathological parameters and the expression of TNF- $\alpha$, IL1- $\beta$, Il-6 were significantly higher on wounds of group IV then in the other groups.

CONCLUSION: Honey of Melipona scutellaris was effective in the management of infected wounds, by significant bacterial growth inhibition, enhancement of cytokine expression, and positively influenced the wound repair.

Key words: Honey. Wound Healing. Cytokines. Infection. Rats. 


\section{Introduction}

All wounds become contaminated, regardless of prevention strategies. Sources of contamination include the local environment, the surrounding skin, and endogenous patient sources ${ }^{1}$. Unfortunately, health care providers remain an important vector for wound contamination ${ }^{2}$. It is well known that Staphylococcus aureus is the most common pathogen causing these infections and it is able to adapt rapidly to selective antibiotics, resulting in the emergence and spread of methicillin resistant S. aureus (MRSA) ${ }^{3}$.

This has become a severe health problem prompting the search for alternative antimicrobials with a new mode of action. Among them, increasing attention is currently given to antiinfective drugs based upon naturally occurring peptides. Several alternative therapies have been tested, among which the topical use of substances with high osmolarity ${ }^{4}$, with sugar and its derivatives cited as healing and antimicrobial agents ${ }^{5,6}$.

Accordingly, the use of honey as a therapeutic element has shown promising results. It has been demonstrated their activity as antibacterial and wound healing agent and in the treatment of burn wounds, acting as an important viscous barrier, preventing the entry of substances and fluid loss to the external environment ${ }^{7}$. Honey's antibacterial activity is due in part to its high osmolarity, which makes it act as bacteriostatic and bactericidal ${ }^{7}$. Studies have pointed that honey is effective against antibiotic-resistant bacteria such as Staphylococcus aureus and Pseudomonas aeruginosa ${ }^{8,9}$.

Melipona scutellaris is a wild stingless bee, known as Uruçu, common in semi-arid region of Northeast Brazil. Its honey has been used empirically in folk medicine to treat respiratory diseases, skin and soft tissue diseases. Very few studies highlight the use of Brazilian honeys for potential wound care ${ }^{10,11}$. This is important, given that most Brazilian people who cannot afford appropriate medical care use their locally produced honeys (Melipona subnitida, Melipona scutellaris, etc) for various therapeutic purposes without knowing their effects, and the scientific mechanisms behind their activity.

In the light of the above, the aim of this study was to examine the effects of Melipona scutellaris honey in the treatment of experimentally induced infected skin wound model in rats.

\section{Methods}

The study was approved by the institutional animal research ethics committee and 3R's principle were adhered to.

Twenty four adult male Wistar rats weighting 250$350 \mathrm{~g}$ were used for all the experiments performed at Nucleus of
Experimental Surgery, Universidade Federal do Rio Grande do Norte (UFRN). All animals were housed in individual cages under constant temperature $\left(22^{\circ} \mathrm{C}\right)$ and humidity with 12 -h light/dark cycle, and had ad libitum access to chow and water throughout the study.

\section{Experimental design}

The rats were randomly selected and allocated into four groups of six rats each. A power calculation based on earlier studies suggested that 6 animals in each group would be sufficient to detect a statistically significant difference in bacterial count, which was the primary outcome in this study. Group I - rats with uninfected wounds submitted to topical treatment with $0.9 \%$ saline solution. Group II - infected wounds treated with saline. Group III - uninfected wounds treated with honey. Group IV - infected wounds treated with honey.

\section{Surgical wounds and treatment}

Rats were anesthetized by an intraperitoneal injection of ketamine ( $70 \mathrm{mg} / \mathrm{kg}$ of b. w.) and xylazine ( $5 \mathrm{mg} / \mathrm{kg}$ of b.w.), the hair on their back was shaved and the skin cleansed with $70 \%$ alcohol solution. Using a $1.0 \mathrm{~cm}$ x $2.0 \mathrm{~cm}$ template, one full thickness wound was established through the panniculus carnosus on the back subcutaneous tissue (one wound per animal). Small gauze was placed over each wound and then inoculated with $5 \times 10^{7} \mathrm{CFU}$ of Staphylococcus aureus ATCC 43300 (The methicillin-resistant S. aureus ATCC 43300 strain was commercially available). in the control group the gauze was soaked only with sterile saline $0.9 \%$ solution. The pocket was closed by means of 4-0 nylon sutures and this procedure resulted in a local abscess after $24 \mathrm{~h}$. The rats were returned to individual cages and they were examined daily. After $24 \mathrm{~h}$, the wounds were opened, the gauze removed for quantitative bacterial cultures and treatment started. Postoperative pain was controled with meperidine (Roche Farma, Brazil.); 10 mg/kg were injected subcutaneously once daily for three days.

In groups III and IV rats a thin layer of pure undiluted Melipona scutellaris honey $(0.1 \mathrm{ml} / \mathrm{cm} 2)$ was applied topically to the wound and filled up the wound. It was then covered with plain gauze. In groups I and II the same volume of sterile saline was used. This treatment was applied once a day for 7 days. The Melipona scutellaris honey was purchased from certified institution, sterilized by x-ray and stored in clean, sterilized bottle at $4^{\circ} \mathrm{C}$ until use. 


\section{Microbiological examination}

At the end of $7^{\text {th }}$ day of treatment, after the last topical application, a sample tissue was taken from each wound, homogenized, weighed and 1:4 wt/vol dilutions were made with sterile $0.9 \%$ saline. Quantization of viable bacteria was performed by culturing ten-fold dilutions of each sample. $0.1 \mathrm{ml}$ of the bacterial suspension from each group was put in sterile blood agar flat bottom plates. All plates were incubated at $37^{\circ} \mathrm{C}$ for 48 $\mathrm{h}$ and evaluated for the presence of the Staphylococcal strain. The number of colony-forming units/g (CFUs/g) of tissue homogenate was used to express the colonization.

\section{Cytokine analysis}

The animals were humanely killed with thiopental $100 \mathrm{mg} / \mathrm{Kg}$ i.p. A $1 \mathrm{~cm} \times 2 \mathrm{~cm}$ area of skin, including the wound was excised aseptically. Half of the wound was used for measurement of tissue cytokines and other half for histopathology. Samples were homogenized in $1 \mathrm{ml}$ PBS using a tissue homogenizer (OMNI, USA) and were used for dosage by ELISA of tumor necrosis factor- $\alpha$ (TNF- $\alpha$ ), interleukin-1ß (IL-1ß) and interleukin 6 (IL-6 ), using PreproTec Kits, (Rocky Hill, NJ,USA).

\section{Histological examination of excised tissues}

In order to histologically assess the effects of different treatment modalities on the healing process of infected wounds, samples were routinely processed. Excised wound tissues were fixed in $10 \%$ buffered formalin, dehydrated in alcohol, cleared in xylene and paraffin-embedded. Five micrometers tissue sections, including the epidermis, the dermis, and the subcutaneous panniculus carnosus muscle, were cut and stained with haematoxylyn and eosin and Masson's Trichrome. All subsequent analyses were performed by an observer blinded to treatment. The specimens were assessed under light microscopy.

The quantitative analysis was made as to the amount of leukocytes, fibroblasts and collagen fibers, using a scanner system, and an image analyzer. The total area of the microscopic fields was observed under an optical microscope (Olympus BX50), whose image was captured by Olympus SC30 camera and scanned by the software Image Pro Plus 6.0 (Media Cybernetics- LP, USA). Each scanned field was quantified in pixels with defined coordinates, being evaluated five random microscopic fields per slide. After selecting the desired resolution, the images were stored to quantify the density of histological data.

Statistical analysis was performed with SPSS 20.0 software (IBM, USA) using the one-way analysis of variance (ANOVA) followed by the multiple comparison Tukey's test, considering significant differences at $\mathrm{p}<0.05$.

\section{Results}

\section{Microbiology}

No animals died due to infection or anesthetics. The culture at $24 \mathrm{~h}$ after wounds inoculation of groups II and IV rats with MRSA showed CFU/g count $>1.000$. In the $7^{\text {th }}$ day, the uninfected wounds treated with saline or with honey had no $\mathrm{CFU} / \mathrm{g}$ of $S$. aureus count. In group II rats whose wounds were infected and treated with saline the counts of $S$. aureus cultured in the wound tissues were significantly higher than in the infected wounds of group IV rats, treated with Melipona Scutellaris honey $(\mathrm{p}<0.01$, Table 1$)$.

TABLE 1 - Wound bacterial count after treatment with saline and Melipona Scutellaris honey.

\begin{tabular}{cc}
\hline Groups - wound treatment & $\begin{array}{c}\text { Wound bacterial count } \\
\text { (CFU/g) }\end{array}$ \\
\hline I - Uninfected, treated with saline & $0 \pm 0$ \\
II - Infected, treated with saline & $1320 \pm 225.3^{*}$ \\
III - Uninfected, treated with honey & $0 \pm 0$ \\
IV - Infected, treated with honey & $185 \pm 41.2$ \\
\hline
\end{tabular}

CFU, Colony-forming units. ${ }^{*} \mathrm{p}<0.01$ vs group IV

Assay of TNF- $\alpha, I L-1 \beta$ and IL-6 in tissue

The treatment of uninfected wounds with honey (group III) stimulated the expression of TNF- $\alpha$ and IL-1ß cytokines. Comparing the values with those observed in the uninfected saline treated wounds (group I), the differences were statistically significant $(\mathrm{p}<0.05)$. No significant difference of IL-6 tissue dosage was observed in group III rats compared to groups I (control) and II. In the scar tissue of infected wounds treated with honey (group IV) we observed a significant increase $(\mathrm{p}<0.05)$ in expression of TNF- $\alpha$, IL-1ß and IL- 6 compared with infected and uninfected wounds of the other groups (I, II, III) (Table 2). 
TABLE 2 - Cytokine concentrations in wound tissue at 7 days post-infection as measured by ELISA $(\mathrm{pg} / \mathrm{mL})$.

\begin{tabular}{cccc}
\hline $\begin{array}{c}\text { Groups - wound } \\
\text { treatment }\end{array}$ & TNF-a & IL-1ß & IL-6 \\
\hline $\begin{array}{c}\text { I-Uninfected, } \\
\text { treated with saline }\end{array}$ & $110 \pm \mathbf{7 3 . 9}$ & $50.2 \pm 8.4$ & $68 \pm 7.7$ \\
$\begin{array}{c}\text { II-Infected, treated } \\
\text { with saline }\end{array}$ & $97 \pm 13$ & $73 \pm 8.2$ \\
$\begin{array}{c}\text { III-Uninfected, } \\
\text { treated with honey } \\
\text { IV-Infected, treated } \\
\text { with honey }\end{array}$ & $101 \pm \mathbf{5 . 2 *}$ & $80 \pm 7.8^{*}$ & $64 \pm 7.6$ \\
\hline
\end{tabular}

* Denotes $\mathrm{p}<0.05$ one-way ANOVA with Tukey's post-test compared to group I; $* * \mathrm{p}<0.05$ comparing with groups I, II, III.

\section{Histopathology}

Treatment of infected wounds with honey (group IV) resulted in density of healing parameters, (collagen, leukocytes and fibroblasts) significantly higher than in the other groups $(p<0.01)$. The treatment of uninfected wounds of group III rats with honey has raised collagen, fibroblasts and white blood cells with higher density than in group I and II, featuring significant difference $(p<0.01)$ (Table 3$)$.

TABLE 3 - The biological impact of different treatments on density of wound healing parameters. Treated and untreated wounds of rats with Melipona scutellaris honey.

\begin{tabular}{cc}
\hline Groups - wound treatment & $\begin{array}{c}\text { Density of healing } \\
\text { parameters }\end{array}$ \\
\hline I-Uninfected, treated with saline & $542.3 \pm 54.1^{*}$ \\
II-Infected, treated with saline & $298.1 \pm 26.2^{*}$ \\
III-Uninfected, treated with honey & $711.84 \pm 68.9^{*}$ \\
IV-Infected, treated with honey & $1032.59 \pm 7.2^{*}$ \\
\hline
\end{tabular}

Mean \pm standard deviation ( $95 \%$ confidence interval);

Values followed by $(*)$ show statistically significant difference by the multiple comparison Tukey test $(\mathrm{p}<0.01)$

\section{Discussion}

We studied the effect of Melipona scutellaris honey on infected wound healing, mainly MRSA staphylococcal infection. Our interest for honey is primarily due to their strong activity mainly against Gram-positive bacteria ${ }^{4,5}$. The honey investigated in this study showed potential for developing into a therapeutically valuable antimicrobial agent particularly indicated for treatment of infected surface lesions such as infected surgical skin wounds, diabetic foot ulcers, foot ulcers in elderly, etc. In this study, we studied the effects of Melipona scutellaris honey in infected wounds. It is a wild stingless bee, known as Uruçu, common in semi-arid region of Northeast, Brazil. Its honey has been used empirically in folk medicine to treat respiratory diseases, skin and soft tissue diseases, and there are not reports in the literature about its use for treatment of clean and infected wounds. Prior physicochemical analysis of Melipona scutellaris honey ${ }^{10}$ revealed that their quality was according to the Technical Regulation of Identity and Quality of Honey, Ministry of Agriculture ${ }^{12}$.

Honey is composed of about $40 \%$ fructose, $20 \%$ water, amino acids, vitamins (nicotinic acid, pyridoxine, and thiamine), enzymes (diastase, invertase, catalase, and glucose oxidase), hydrogen peroxide, and minerals (potassium, iron, magnesium, phosphorus, copper, zinc and calcium) ${ }^{13}$. In our study, the microbiological evaluation of infected wounds in groups III and IV rats showed antimicrobial activity of Melipona scutellaris honey against MRSA. The results of this study showed that honey has clinical potential to be used to prevent and control Grampositive infections (Staphylococcus). In vitro study conducted by French et al..$^{14}$ demonstrated that honey was antimicrobial effect in coagulase-negative Staphylococcus.

The antibacterial activity of honey is related with some properties: it is a supersaturated solution with strong osmotic activity, the $\mathrm{pH}$ is between 3.2 and 4.5 , and this acidity is sufficient to inhibit the growth of many microorganisms. In our laboratory ${ }^{10}$ we demonstrated that the $\mathrm{pH}$ of $M$. scutellaris honey was 3.85 . Hydrogen peroxide produced by glucose oxidase is certainly the most important antibacterial factor of honey and several other phytochemicals and immunochemical factors are being evaluated ${ }^{15}$. Comparative study of honey and sugar showed that honey is more effective against wound infections ${ }^{16}$. A study conducted in our laboratory using Melipona subnitida honey, another wild stingless bee, known as Jandaíra, common in semi-arid region of Northeast Brazil, demonstrated significant antimicrobial effect in skin infected wounds ${ }^{11}$.

In the present study the histopathology of infected wounds and treated with honey revealed a significant increase in of leukocytes, particularly macrophages, fibroblasts and collagen in the examined tissues. Macrophages are important cells for the regulation of wound healing, so that topical substances that activate macrophages can generate pro-inflammatory stimuli, cell proliferation and enhancement of healing ${ }^{17}$.

Established the positive effects of honey in clean and infected wounds, the mechanisms responsible for healing 
and antimicrobial activity deserve to be clarified. Studies have shown that the effect of honey in wound healing can be related to the increased release of TNF- $\alpha^{18}$. In the current study we could demonstrate that TNF- $\alpha$ had the highest expression of cytokines in tissues of infected wounds treated with honey, followed by IL-1 $\beta$ and IL-6. This finding may in part explain the positive result in the healing of these wounds when compared to those untreated with honey.

Tonks et al. ${ }^{18}$ used honey bee and artificial honey to elicit the release of TNF-a, IL-1 $B$ and IL- 6 production by monocytes. It was suggested that the regulatory effects of honey on wound healing are related to other components in addition to the sugars present in honey, some still unknown factors that induce the release of cytokines. Their study demonstrated that the activity of monocytes, intimately involved in wound healing, is modulated by the honey. So, natural honey samples that were tested have a stimulatory effect with regard to the production of TNF- $\alpha$, IL-1ß and IL- 6 by monocytic cells. The cytokines involved are both pro and anti-inflammatory ${ }^{18}$. These cytokines modulate the activity of many cell types that are intimately involved in the regeneration of tissue $^{19}$. Macrophages are central to the regulation of cutaneous wound healing, and dressings that elicit macrophage activation ${ }^{17}$ may generate a pro-inflammatory stimulus in non-healing wounds, which resolves the chronic inflammatory status towards cell proliferation and progression into the healing phase.

TNF- $\alpha$ is a pleiotropic, pro-inflammatory cytokine, with the ability to affect almost every tissue and organ system. This pluripotent protein is chemotactic for macrophages and promotes macrophage activation. It stimulates angiogenesis ${ }^{20}$, and fibroblast proliferation $^{21}$. It has also been suggested that the stimulation of TNF- $\alpha$ production may exert much of its beneficial effects by affecting the increasing levels of IL-6, that is released in response to multiple stimuli, with TNF- $\alpha$, IL- $1 \beta$ and endotoxins being potent agonists ${ }^{22}$. Thus TNF- $\alpha$, through its important effects on the recruitment of inflammatory cells and on the substrate metabolism, seems to be essential in promoting the early inflammatory response required for wound healing. However, its local and systemic persistence may lead to impaired wound maturation. In the current work we studied wound healing until the seventh day, consequently we observed the beneficial effects of high levels of TNF- $\alpha$ on early healing tissues. IL-6 is an other pleiotropic cytokine with significant impact on healing. It is mitogenic for keratinocytes ${ }^{23}$, and its contribution to epithelialisation has been demonstrated. Interstingly, TNF- $\alpha$ also induces IL-6 production by keratinocytes, indicating an important synergistic relationship between these two cytokines; it also stimulates reepithelialisation ${ }^{24}$.
No study has been undertaken to test the antimicrobial efficacy of Melipona scutellaris honey against bacteria commonly residing in acute and chronic wounds, such as Staphylococcus aureus. As methicillin-resistant S. aureus (MRSA) has become a severe health problem prompting the search for alternative antimicrobials solutions, we have chosen MRSA to test Melipona scutellaris honey as a potential anti-infective agent. Geopropolis of $M$. Scutellaris has been studied and showed antimicrobial and antiproliferative activity ${ }^{25}$.

\section{Conclusion}

Honey of Melipona scutellaris is effective in the management of infected wounds, by a significant bacterial growth inhibition, and positively influences the cytokine expression and wound repair.

\section{References}

1. Leclère $\mathrm{B}$, Lasserre $\mathrm{C}$, Bourigault $\mathrm{C}$, Juvin ME, Chaillet MP, Mauduit N, Caillon J, Hanf M, Lepelletier D; SSI Study Group. Matching bacteriological and medico-administrative databases is efficient for a computer-enhanced surveillance of surgical site infections: retrospective analysis of 4,400 surgical procedures in a French university hospital. Infect Control Hosp Epidemiol. 2014 Nov;35(11):1330-5. doi: 10.1086/678422.

2. Kumar S, van Popta D, Rodrigues-Pinto R, Stephenson J, Mohammad $\mathrm{S}$, Siddique I, Verma RR. Risk factors for wound infection in surgery for spinal metastasis. Eur Spine J. 2015 Mar;24(3):528-32. doi: 10.1007/s00586-013-3127-4.

3. Herrera M, Di Gregorio S, Fernandez S, Posse G, Mollerach M, Di Conza J. In vitro selection of Staphylococcus aureus mutants resistant to tigecycline with intermediate susceptibility to vancomycin. Ann Clin Microbiol Antimicrob. 2016 Mar 8;15(1):15. doi: 10.1186/ s12941-016-0131-7.

4. Vermeulen H, UbbinkDT, Goossens A, de Vos R, Legemate DA. Systematic review of dressings and topical agents for surgical wounds healing by secondary intention. Br J Surg. 2005;92(6):66572. PMID: 15912490.

5. Blaser G, Santos K, Bode U, Vetter H, Simon A. Effect of medical honey on wounds colonised or infected with MRSA. J Wound Care. 2007;16(8):325-8. PMID: 17927079.

6. Coelho COC, Carrazoni PG, Monteiro VLC, Melo FAD, Mota A, Filho FT. Biopolímero produzido a partir da cana-de-áçucar para cicatrização cutânea. Acta Cir Bras. 2001;17(Supl. 1):11-3. PMID: 17929079.

7. Subrahmanyam M. Honey dressing accelerates split-thickness skin graft donor site healing. Indian J Surg. 2015 Dec;77(Suppl 2):261-3. doi: 10.1007/s12262-012-0789-9.

8. Ewnetu Y, Lemma W, Birhane N. Antibacterial effects of Apis mellifera and stingless bees honeys on susceptible and resistant strains of Escherichia coli, Staphylococcus aureus and Klebsiella pneumoniae in Gondar, Northwest Ethiopia. BMC Complement Altern Med. 2013 Oct 19;13:269. doi: 10.1186/1472-6882-13-269.

9. Cooper RA, Molan PC, Harding KG. Honey and gram positive cocci of clinical significance in wounds. J Appl Microbiol. 2002;93(5): 857-63. PMID: 12392533. 
10. Medeiros VFLP, Rego ACM, Araujo-Filho I, Medeiros VB, Medeiros AC. Physicochemical attributes and quality of the Melipona scutellaris honey: comparison with Brazilian regulatory standards. J Surg Cl Res. 2015;6:57-63. doi: 10.20398/jscr.v6i2.8628.

11. Alves D FS, Cabral-Jr FC, Cabral PPAC, Rego ACM, Medeiros A C. Effects of topical application of the honey of Melipona subnitida in infected wounds of rats. Rev Col Bras Cir. 2008; 35:188-93.

12. Brasil. Ministério da Agricultura. Instrução normativa 11, de 20 de outubro de 2000. Regulamento técnico de identidade e qualidade do mel. Diário Oficial, Brasília, 20 de outubro de 2000, Seção 1, p.167.

13. Ruiz-Matute AI, Weiss M, Sammataro D, Finely J, Sanz ML. Carbohydrate composition of high-fructose corn syrups (HFCS) used for bee feeding: effect on honey composition. J Agric Food Chem. 2010 Jun 23;58(12):7317-22. doi: 10.1021/jf100758x.

14. French VM, Cooper RA, Molan PC. The antibacterial activity of honey against coagulase-negative staphylococci. J Antimicrob Chemother. 2005;56(1):228-31. PMID: 15941774.

15. Park D, Jung JW, Lee MO, Lee SY, Kim B, Jin HJ, Kim J, Ahn YJ, Lee KW, Song YS, Hong S, Womack JE, Kwon HW. Functional characterization of naturally occurring melittin peptide isoforms in two honey bee species, Apis mellifera and Apis cerana. Peptides. 2014 Mar;53:185-93. doi: 10.1016/j.peptides.2014.01.026.

16. Mphande AN, Killowe C, Phalira S, Jones HW, Harrison WJ. Effects of honey and sugar dressings on wound healing. J Wound Care. 2007;16(7):317-9. PMID: 17708384.

17. Thomas A, Harding KG, Moore K. Alginates from wound dressings activate human macrophages to secrete tumour necrosis factoralpha. Biomaterials. 2000;21:1797-802. PMID: 10905462.

18. Tonks AJ, Cooper RA, Jones KP, Blair S, Parton J, Tonks A. Honey stimulates inflammatory cytokine production from monocytes. Cytokine. 2003;21(5):242-7. PMID: 12824009.

19. Patel S, Maheshwari A, Chandra A. Biomarkers for wound healing and their evaluation. J Wound Care. 2016 Jan;25(1):46-55. doi: 10.12968/jowc.2016.25.1.46.

20. Wang H, Han X, Wittchen ES, Hartnett ME. TNF- $\alpha$ mediates choroidal neovascularization by upregulating VEGF expression in RPE through ROS-dependent $\beta$-catenin activation. Mol Vis. 2016 Feb 3;22:116-28. PMID: 26900328.

21. Zhou B, Zhuang XM, Wang YY, Lin ZY, Zhang DM, Fan S, Li JS, Chen WL. Tumor necrosis factor $\alpha$ induces myofibroblast differentiation in human tongue cancer and promotes invasiveness and angiogenesis via secretion of stromal cell-derived factor-1. Oral Oncol. 2015 Dec;51(12):1095-102. doi: 10.1016/j. oraloncology.2015.08.017.
22. Werner S, Grose R. Regulation of wound healing by growth factors and cytokines. Physiol Rev. 2003;83:835-70. PMID: 12843410.

23. Gallucci RM, Sloan DK, Heck JM, Murray AR, O'Dell SJ. Interleukin 6 indirectly induces keratinocyte migration. J Invest Dermatol. 2004;122:764-72. PMID: 15086564.

24. Banno T, Gazel A, Blumenberg M. Effects of tumor necrosis factoralpha (TNF alpha) in epidermal keratinocytes revealed using global transcriptional profiling. J Biol Chem. 2004;279:32633-42. PMID: 15145954.

25. da Cunha MG, Franchin M, de Carvalho Galvão LC, de Ruiz AL, de Carvalho JE,Ikegaki M, de Alencar SM, Koo H, Rosalen PL. Antimicrobial and antiproliferative activities of stingless bee Melipona scutellaris geopropolis. BMC Complement Altern Med. 2013 Jan 28;13:23. doi: 10.1186/1472-6882-13-23.

\section{Correspondence:}

Aldo Cunha Medeiros

Avenida Nilo Peçanha 620

59012-300 Natal-RN Brasil

cirurgex.ufrn@gmail.com

Received: Jan 22, 2016

Review: Mar 19, 2016

Accepted: Apr 18, 2016

Conflict of interest: none

Financial source: CNPq (Grant 4449083/2014-4)

${ }^{1}$ Research performed at Nucleus of Experimental Surgery, Department of Surgery, Universidade Federal do Rio Grande do Norte (UFRN), NatalRN, Brazil. Part of PhD degree thesis, Postgraduate Program in Health Sciences. Tutor: Aldo Cunha Medeiros. 